\title{
Effect of Aerosolized Uridine 5'-Triphosphate on Mucociliary Clearance in Mild Chronic Bronchitis
}

\author{
WILLIAM D. BENNETT, KIRBY L. ZEMAN, CARLA FOY, CHRISTY L. SHAFFER, FRED L. JOHNSON, JEFF A. REGNIS, \\ ARUNA SANNUTI, and JANA JOHNSON
}

Division of Pulmonary Diseases, Department of Medicine, University of North Carolina at Chapel Hill, Chapel Hill, North Carolina; and Inspire Pharmaceuticals, Inc., Durham, North Carolina

\begin{abstract}
Previous studies show that uridine 5 '-triphosphate (UTP), a P2Y 2 receptor agonist, is effective at acutely enhancing mucociliary clearance in healthy, nonsmoking adults. UTP solution for inhalation is being developed by Inspire Pharmaceuticals under the compound number INS316. In a double-blind, randomized, crossover, placebo-controlled study we tested the single-dose effect of UTP in chronic smokers with mild chronic bronchitis $(n=15)$ by measuring the clearance of ${ }^{99 \mathrm{~m}} \mathrm{Tc}_{\mathrm{c}} \mathrm{Fe}_{2} \mathrm{O}_{3}$ particles $(4.0 \mu \mathrm{m}$ mass median aerodynamic diameter [MMAD]) after inhalation of nebulized placebo ( $0.9 \%$ saline) and two doses of UTP (20 and $100 \mathrm{mg}$ in the nebulizer). On each study day, gamma camera scanning was performed over a 2-h period. After an initial deposition scan, subjects inhaled placebo or UTP during the first $\mathbf{2 0}$ min of scanning. Analysis of whole lung clearance showed that the retention-time curves for each day were biphasic and that the earliest break point in the average curves occurred at $50 \mathrm{~min}$. Mean particle clearance rate (Clr in \%/min) through $50 \mathrm{~min}$ for placebo treatment was $\mathrm{Clr}=$ $0.65 \pm 0.27$ whereas treatment with UTP showed Clr significantly increased to $0.95 \pm 0.48$ and $0.93 \pm 0.44$ for the $20-\mathrm{mg}$ and 100 mg dose respectively, $\mathrm{p}<0.005$ for both as compared with placebo. These data show that mucociliary clearance associated with mild chronic bronchitis is acutely improved with minimal doses of aerosolized UTP, presumably because of its stimulation of ciliary beating and hydration of airway secretions.
\end{abstract}

Keywords: uridine 5'-triphosphate; mucus clearance; safety

Recent in vitro data indicate that triphosphate nucleotides such as adenosine triphosphate (ATP) and uridine 5' -triphosphate (UTP) interact with extracellular purinergic receptors $\left(\mathrm{P} 2 \mathrm{Y}_{2}\right)$ and initiate $\mathrm{Cl}^{-}$secretion on the apical membrane of human airway epithelia $(1,2)$. This enhanced $\mathrm{Cl}^{-}$secretion has been shown to result in increased hydration of the airway surface (2). Studies of normal airway epithelia have also shown that triphosphate nucleotides are capable of stimulating ciliary beat frequency (CBF) (3) and goblet cell degranulation (4). These integrated effects of UTP on the airway epithelium may thereby facilitate impaired mucociliary clearance.

Impaired mucociliary clearance may contribute to the pathophysiology of several airway diseases such as chronic bronchitis, cystic fibrosis, and asthma. We recently showed that UTP dramatically stimulated mucociliary clearance (MCC) in normal subjects (5) and that UTP enhances cough clearance in patients with primary ciliary dyskinesia (PCD) (6). Because patients with PCD have dysfunctional cilia, they must rely on cough to clear secretions from the surface of their airways. However, UTP may not be suitable as a therapeutic agent in the

(Received in original form August 15, 2000 and in revised form March 15, 2001)

Supported by Inspire Pharmaceuticals, Inc.

Correspondence and requests for reprints should be addressed to William D. Bennett, Ph.D., Center for Environmental Medicine, CB 7310, 104 Mason Farm Rd., University of North Carolina at Chapel Hill, Chapel Hill, NC 27599.

Am J Respir Crit Care Med Vol 164. pp 302-306, 2001

Internet address: www.atsjournals.org treatment of chronic bronchitis and other obstructive pulmonary diseases because the compound is rapidly degraded enzymatically within sputum and by airway epithelial cells (7). Inspire Pharmaceuticals is developing enzymatically resistant, longer acting $\mathrm{P} 2 \mathrm{Y}_{2}$ agonists for these indications. Because of its rapid onset and expected short duration of action, UTP is being developed (under the compound number INS316) as an agent for obtaining deep-lung sputum specimens suitable for diagnostic purposes such as for the cytologic detection of lung cancer. In the present study, we measured the acute effect of aerosolized UTP on the MCC of radiolabeled particles in smokers with mild chronic bronchitis, a population likely to be evaluated for the presence of lung cancer by sputum cytology.

\section{METHODS}

\section{Subjects}

Fifteen ( 8 female/7 male) subjects with mild chronic bronchitis (mean age 43 yr, range 32 to 54) were studied. All patients had a clinical diagnosis of chronic bronchitis based on the American Thoracic Society (ATS) definition, i.e., excess mucus production, occurring on most days for at least 3 mo of the year for at least two successive years. All were current, chronic smokers $(27 \pm 12$ pack-years) with normal lung function $\mathrm{FEV}_{1}$ percentage of predicted $\geqslant 80 \%$ and maximal midexpiratory flow (MMEF) percentage of predicted of $80 \pm 23$. Subjects had no acute respiratory exacerbation for $4 \mathrm{wk}$ before testing. None of the subjects was taking inhaled or oral bronchodilators during the period of their study. The study was approved by the University of North Carolina Committee on the Protection of the Rights of Human Subjects and informed consent was obtained.

\section{Protocol}

Subjects were studied on a control (i.e., no treatment) day and on three treatment days in a crossover design. The three treatment days ( $0.9 \%$ saline, $20 \mathrm{mg}$ UTP, and $100 \mathrm{mg}$ UTP) were randomized, double-blinded, and separated by no more than $1 \mathrm{wk}$. The $20-\mathrm{mg}$ dose was similar to that used in previous studies of normal and PCD subjects without any adverse effects $(5,6)$. The $100-\mathrm{mg}$ dose was found to be safe and well tolerated in a dose-escalating study of aerosolized UTP in a similar group of chronic bronchitics as those studied here (8).

On each study day the subject breathed a $4.0 \mu \mathrm{m}$ mass median aerodynamic diameter (MMAD) (geometric standard deviation $=1.25$ ) aerosol of insoluble iron oxide radiolabeled with technetium- $99 \mathrm{~m}\left({ }^{99 \mathrm{~m}} \mathrm{Tc}\right)(5$, 6). To match airway deposition of the aerosol on the four study days, tidal flow $(500 \mathrm{ml} / \mathrm{s})$ and breathing frequency $(30 / \mathrm{min})$ were controlled by having the patient monitor tidal flow on an oscilloscope. Subjects inhaled the aerosol for a maximum of $5 \mathrm{~min}$ to deposit sufficient radioactivity (approximately $20 \mu \mathrm{Ci}$ ) in the lung for clearance measurements. With the subject seated in front of the gamma camera (Elscint Apex 415 gamma camera interfaced with an Elscint Model 109 computer; Elscint, Haifa, Israel), an initial deposition scan (the sum of two 2-min scans) was recorded and then continuous 2-min images were recorded for a period of $2 \mathrm{~h}$. Subjects also returned at $24 \mathrm{~h}$ postdeposition for a 30-min scan.

After the initial deposition scan on the treatment study days, the patient received the randomized, aerosol treatment delivered by PARI LC Plus Jet nebulizer (PARI, Midlothian, VA) (4 $\mathrm{ml}$ of $0.9 \%$ saline, $5-\mathrm{mg} / \mathrm{ml} \mathrm{UTP}$, or $20-\mathrm{mg} / \mathrm{ml}$ UTP) during tidal breathing over a $15-\mathrm{min}$ period. Some uncontrollable, spontaneous coughing occurred during 
the aerosolized treatments. The frequency and times of these coughs were recorded for comparison between the four study days. To assess the safety of each single-dose UTP treatment (and placebo), we monitored oxyhemoglobin saturation and blood pressure throughout the dosing period and until the end of the gamma camera monitoring, and measured forced expiratory volumes and flows by spirometry before and immediately after MCC measures.

The nebulizer was powered by a DeVilbiss Pulmoaide compressor (De Vilbiss, Somerset, PA). Particle size of the UTP solution droplets was determined by complete drying of particles after nebulization followed by cascade impaction of the dried particles. The original droplet size distribution was then calculated from the "dry" size distribution and the original mass concentration of the solution (9). For these measurements we determined a mean particle size of 3.6 $\mu \mathrm{m}$ MMAD and a geometric standard deviation of 1.74 .

\section{Data Analysis}

Significance was set at $\mathrm{p}<0.05$ for two-tailed analysis. Unless otherwise specified, data are presented as means \pm standard deviation of the means.
On the initial study day, a xenon-133 equilibrium lung scan was recorded for each subject $(5,6)$ to create regions of interest for determining regional distribution and retention of the deposited aerosol. Only the right lung was used for analysis because of interference from stomach activity on the left side. To assess the degree of central (C) versus peripheral $(\mathrm{P})$ airway deposition, we calculated a $\mathrm{C} / \mathrm{P}$ ratio of ${ }^{99 m}$ Tc activity $(5,6)$ for the initial 2 -min deposition scan, normalized to the xenon equilibrium scan. The $\mathrm{C} / \mathrm{P}$ ratio was used to determine if initial particle deposition for the four study days was similar.

A rectangular region bordering the whole right lung (defined by the Xe-133 equilibrium scan) was used to determine by computer analysis the lung retention (R), expressed as a percentage of the initial decay-corrected counts, in the right lung over the 2 -h period and at $24 \mathrm{~h}$. Analysis of regional clearance was performed by constructing a smaller rectangular region (approximately $25 \%$ by area of the whole right lung region) to define the central region $(5,6)$. Clearance from both the central and the outer peripheral region (lying between the central and the whole lung rectangle) was also determined. Although both regions overlap bronchial airways as well as parenchyma, the central region contains the largest proximal airways (mainstem and lobar bronchi) not contained in the peripheral zone.

A

\section{Control}

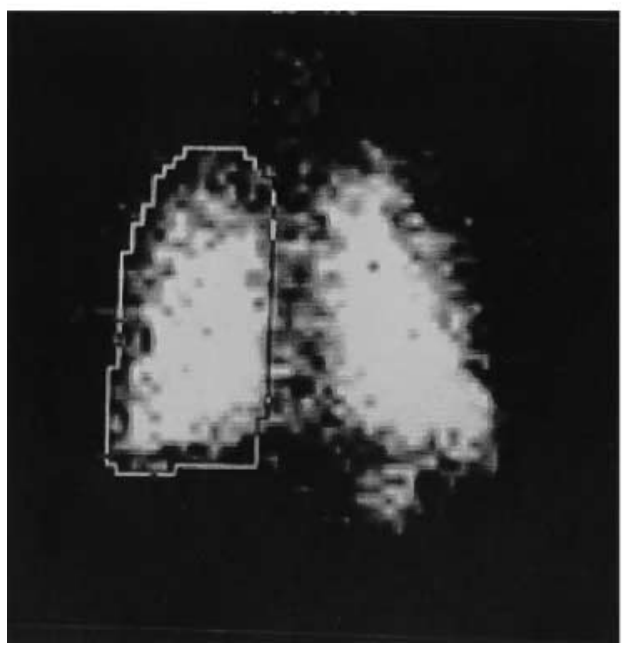

B

\section{Control}

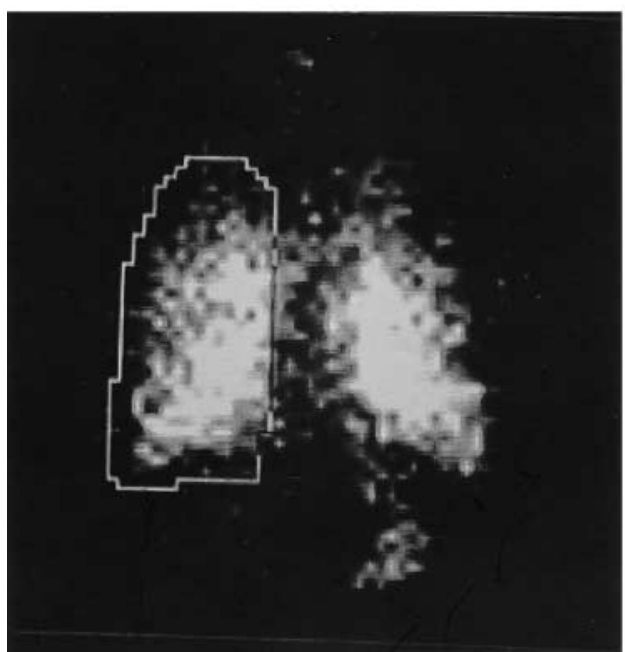

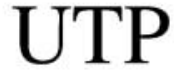
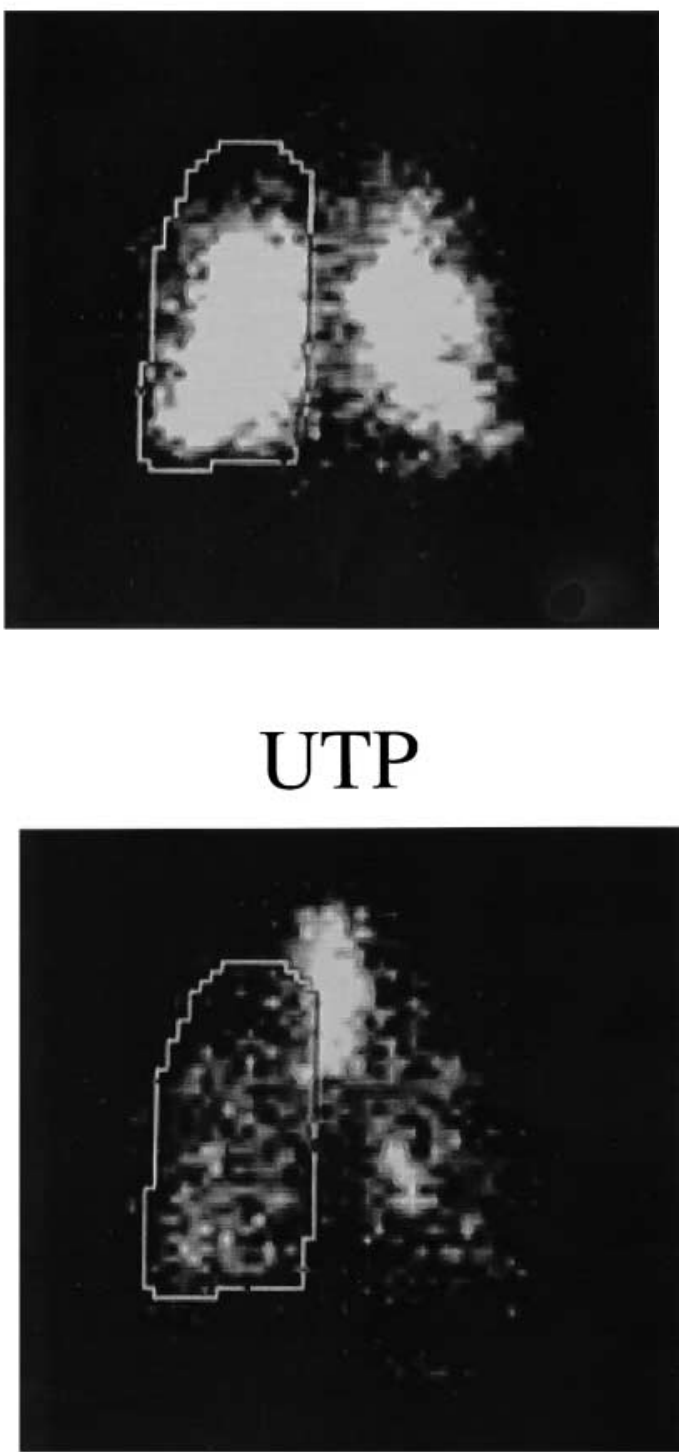

Figure 1. (A) Initial deposition gamma camera images on control (left) and UTP (right) study days of one subject. Region of interest around right lung was created from xenon-133 equilibrium scan. (B) Gamma camera images at 30 min after deposition of radiolabeled particles for control (left) and UTP (right) study days of same subject. 


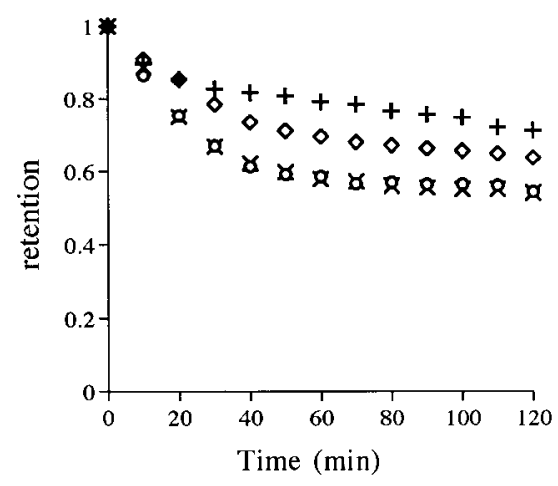

Figure 2. Mean whole lung clearance (retention versus time) for control $(+)$, placebo $(\diamond), 20 \mathrm{mg}$ UTP $(\bigcirc)$, and $100 \mathrm{mg}$ UTP $(\times)$.

By fitting a polynomial to the whole lung retention $(\mathrm{R})$ versus time data from all study days and patients, a change point, defined as the earliest time point for which the quadratic term of time became statistically significant, was estimated (5). The common change point for all treatment study days was estimated to be 50 min (Figure 2), whereas for the control day there was no statistically significant change point in the clearance curve. In each patient a clearance rate ( $\mathrm{Clr}$ in $\% / \mathrm{min})$ was then determined for each study day as the slope of a linear regression through the percent clearance $(100-\mathrm{R})$ versus time data from time $=0$ to $50 \mathrm{~min}$. Similar rates for central and peripheral clearance were determined for each study day in each patient. The same period of interest (i.e., from time $=0$ to $50 \mathrm{~min}$ ) was used for whole, central, and peripheral lung clearance rates so that direct comparisons between regions could also be made. Initial comparisons between different drug treatments were made by repeated measures analysis (Systat for Macintosh; SPSS, Evanston, IL) of Clr, C/P, and 24-h retention for each study day. Comparison of cough frequency on the four study days was made by Friedman nonparametric rank analysis for repeated measures. Multivariate analysis (Systat for Macintosh) was also performed to determine the role of other covariates to any observed differences in $\mathrm{Clr}$ for the different treatment study days. Variables considered were treatment, initial deposition pattern $(\mathrm{C} / \mathrm{P}$ ratio), cough frequency over the period of interest, and interactions between these two variables and treatment.

\section{RESULTS}

Gamma camera images from a representative subject are illustrated in Figure 1. Figure 1A shows initial deposition scans (time 0 ) on a control (i.e., no treatment) versus a UTP study day. Figure $1 \mathrm{~B}$, at $30 \mathrm{~min}$ postdeposition (or approximately 15 min after completion of aerosolized UTP treatment for that day) shows that on the control study day little activity appears to have moved from the region of interest surrounding the right lung into the trachea. On the other hand, by $15 \mathrm{~min}$ after treatment with UTP, a considerable amount of radiotracer has already left the lung in transit up the trachea. Figure 2 illustrates

TABLE 1. SUMMARY OF RESULTS

\begin{tabular}{lcccc}
\hline & Control & Placebo & $20 \mathrm{mg}$ UTP & $100 \mathrm{mg}$ UTP \\
\hline $\begin{array}{l}\text { Whole lung Clr, } \\
\text { \%/min }\end{array}$ & $0.47 \pm 0.21$ & $0.65 \pm 0.27$ & $0.95 \pm 0.48$ & $0.93 \pm 0.44$ \\
$\begin{array}{l}\text { Central lung Clr, } \\
\text { \%/min }\end{array}$ & $0.49 \pm 0.25$ & $0.71 \pm 0.37$ & $1.13 \pm 0.54$ & $1.10 \pm 0.50$ \\
$\begin{array}{l}\text { Peripheral lung } \\
\text { Clr, \% min }\end{array}$ & $0.47 \pm 0.22$ & $0.58 \pm 0.21$ & $0.77 \pm 0.44$ & $0.79 \pm 0.38$ \\
$\begin{array}{l}\text { C/P ratio } \\
\text { 24-h retention }\end{array}$ & $1.35 \pm 0.26$ & $1.38 \pm 0.26$ & $1.46 \pm 0.41$ & $1.40 \pm 0.29$ \\
$\begin{array}{l}\text { Coughs through } \\
\quad 50 \text { min, } \mathrm{n}\end{array}$ & $0.3 \pm 0.12$ & $0.38 \pm 0.12$ & $0.36 \pm 0.14$ & $0.39 \pm 0.12$ \\
\hline
\end{tabular}

mean whole lung clearance of ${ }^{99 \mathrm{~m}} \mathrm{Tc}$-iron oxide for the four study days (control, placebo, and two doses of UTP) in all subjects. Table 1 gives the mean Clr in \%/min, C/P ratios, 24-h retentions, and number of coughs through $50 \mathrm{~min}$ for each study day. By repeated analysis, there were significant differences in Clr for the four study days ( $\mathrm{p}<0.001)$. Post hoc paired comparisons showed that both doses of UTP produced, on average, a $100 \%$ increase in whole lung clearance rate $(\mathrm{Clr})$ compared with control and a $45 \%$ increase compared with placebo $(\mathrm{p}<0.005)$. Whole lung $\mathrm{Clr}$ was, on average, $38 \%$ greater for placebo versus control $(\mathrm{p}<0.01)$. There was no difference in Clr between the two doses of UTP. There was no significant difference in either $\mathrm{C} / \mathrm{P}$ ratios or 24-h retentions between the four study days, but cough frequency was significantly different among the four study days ( $p<0.001$ by Friedman nonparametric rank analysis for repeated measures). Frequency of spontaneous coughing was greater than control for both doses of UTP $(\mathrm{p}<0.001)$ and was UTP dose related, i.e., significantly more coughing with the higher dose of aerosolized UTP $(100-\mathrm{mg})(\mathrm{p}<0.005)$. Despite a tendency for greater cough with the low-dose UTP (20-mg) compared with placebo, the difference was not significant $(p=0.07)$. There was also no difference in cough frequency between placebo and control test days.

Linear regression analysis of the retention versus time data for the period 50 to $120 \mathrm{~min}$ in Figure 1 (i.e., after the change point) for all treatment days showed that the time $=0$ intercept was shifted with both saline and UTP treatment. This shift suggests an increasing portion of the deposited particles being cleared during the fast phase of the clearance curve (i.e., 0-50 min) with all treatments. The percentage of deposited particles being cleared as part of the fast phase of clearance (as estimated from the zero intercept retention versus time over the range 50 to $120 \mathrm{~min}$ ) increased from $12 \%$ for control to $25 \%$ for saline to $38 \%$ for both UTP treatments. Thus, not only did the rate of fast-phase clearance (Clr) increase with UTP treatment (by approximaely $50 \%$ compared with placebo) but the size of the compartment (number of airways) participating in the fast phase of MCC was also increased (also by approximately $50 \%$ ).

Figure 3 illustrates mean central lung clearance for the four study days. Clr from the central lung region were faster than the respective whole lung rates for both doses of UTP but not for control or placebo (Table 1$)(\mathrm{p}<0.001)$. As with whole lung clearance, there were significant differences in central lung $\mathrm{Clr}$ for the four study days $(\mathrm{p}<0.001)$. Both doses of UTP enhanced central lung clearance relative to placebo $(\mathrm{p}<$

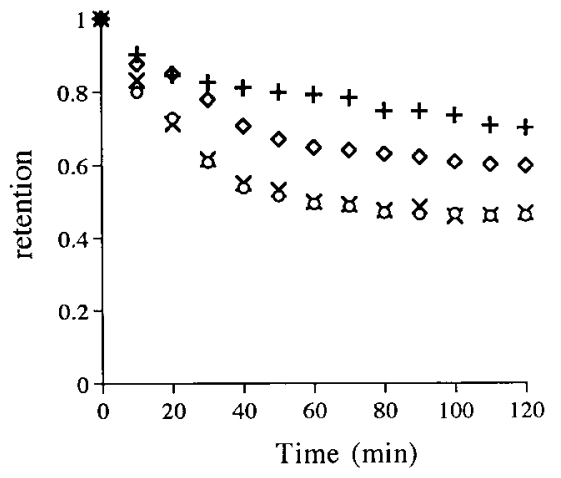

Figure 3. Mean central lung clearance (retention versus time) for control $(+)$, placebo $(\diamond), 20 \mathrm{mg}$ UTP $(\bigcirc)$, and $100 \mathrm{mg}$ UTP $(\times)$. 


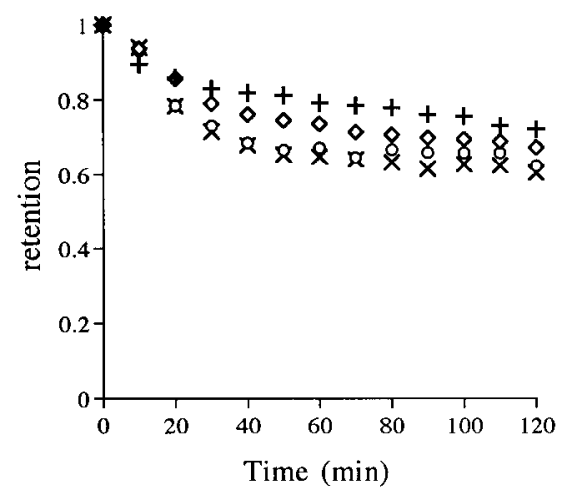

Figure 4. Mean peripheral lung clearance (retention versus time) for control $(+)$, placebo $(\diamond)$, 20-mg UTP $(\bigcirc)$, and 100-mg UTP $(\times)$.

0.001). Similarly, central lung Clr was significantly greater for placebo versus control $(\mathrm{p}<0.01)$.

Figure 4 illustrates mean peripheral lung clearance for the four study days. Clr from the peripheral lung region were slower than the respective whole lung rates for both doses of UTP but not for control or placebo (Table 1) $(\mathrm{p}<0.001)$. As with whole and central lung clearance, there were significant differences in peripheral lung $\mathrm{Clr}$ for the four study days $(\mathrm{p}<$ 0.001). Both doses of UTP enhanced peripheral lung clearance relative to placebo $(\mathrm{p}<0.05)$. Unlike whole lung and central $\mathrm{Clr}$, however, $\mathrm{Clr}$ for the peripheral region was not significantly different $(\mathrm{p}=0.06)$ for placebo versus control.

Multivariate analysis of Clr for the whole lung showed that subject, treatment, and the interaction between treatment and $\mathrm{C} / \mathrm{P}$ ratio accounted for the only significant variation in $\mathrm{Clr}(\mathrm{p}<$ 0.01 in each case). Thus, the differences in Clr within a subject could be primarily explained by treatment with placebo and the two doses of UTP. Also, the variation in $\mathrm{Cl}$ as a function of $\mathrm{C} / \mathrm{P}$ (i.e., slope of $\mathrm{Clr}$ versus $\mathrm{C} / \mathrm{P}$ ) was different for the different treatment arms (i.e., the significant interaction between treatment and $\mathrm{C} / \mathrm{P}$ ratio). This translated into a greater effect of the UTP treatments on Clr for those subjects with higher $\mathrm{C} / \mathrm{P}$ ratios or more central airway deposition. This is consistent with the larger effect of UTP seen on central versus peripheral airway clearance (Figure 2 versus Figure 3 and Table 1). In the multivariate analysis, there was no significant variation in $\mathrm{Clr}$ $(p>0.3)$ associated with $\mathrm{C} / \mathrm{P}$ alone nor the number of coughs in $50 \mathrm{~min}$, either alone or the interaction between treatment and number of coughs. In other words, despite the significant difference in cough number between the different treatment days (Table 1), it was not predictive of the difference in $\mathrm{Clr}$ observed.

The safety measures during the study showed no significant effects of either single-dose UTP treatment on blood pressure. Oxyhemoglobin saturation was transiently decreased below $90 \%$ (range 83 to $89 \%$ ) in some subjects during UTP inhalation and up to $5 \mathrm{~min}$ after completion of dosing. This decrease in oxyhemoglobin saturation seemed to be dose-dependent, occurring in three of 15 subjects for the 20 -mg dose of UTP and in nine of 15 subjects for the 100-mg dose of UTP. No such fall in oxyhemoglobin saturation occurred on the placebo study days. By the end of MCC measures, i.e., $2 \mathrm{hr}$ after dosing, oxyhemoglobin saturation was equal to or greater than predosing values for all treatments. Spirometry measures showed no change in FVC or $\mathrm{FEV}_{1}$ between pre-MCC and post-MCC measures on the UTP or placebo dosing days. There was a trend toward a mild decrease in MMEF, a $6 \%$ decrease $(\mathrm{p}=$ 0.08 ), on the 100-mg UTP treatment day.

\section{DISCUSSION}

Similar to our previous findings in nonsmoking, healthy subjects (5) we have found in the present study that UTP acutely stimulates MCC in mild chronic bronchitics. The relative increase in Clr for the whole lung after UTP administration was similar to that seen previously in the healthy, nonsmoking subjects (5). The 20-mg dose of UTP $(5 \mathrm{mg} / \mathrm{ml})$ used in this study is comparable to the $10^{-2} \mathrm{M}$ solution of UTP used in the previous study (5). Both studies showed an approximate doubling of the rate of clearance during and immediately after UTP inhalation. This similarity to nonsmokers also suggests that degradation of the UTP in airway secretions or epithelial cells in these chronic bronchitics did not occur to a greater extent than likely occurred in the healthy nonsmokers. In the present study, increasing the dose of UTP 5-fold (i.e., to 100-mg) caused no further enhancement of the clearance rate during the period of observation. Thus, it may be that the lower dose of UTP (20-mg) maximally enhances MCC over the 50-min period of observation through its effects on ciliary beat frequency (3) and improved hydration of the airway surface (2).

A single dose of UTP administration to patients with mild chronic bronchitis also produces an acute increase in sputum expectoration (8). This increase may be attributed to improved hydration of secretions (2) or enhanced mucin secretion (4). The mild decreases in oxyhemoglobin saturation and MMEF for the high dose of UTP that we observed may also be a reflection of enhanced secretions in the lung periphery. Though UTP has been demonstrated to stimulate mucin secretion (4), increased mucin secretion alone apparently adds little to the rate of MCC in smokers already exhibiting more mucus on their airways than normal $(10,11)$. Increased mucus secretion in healthy airways with a less continuous mucus blanket, on the other hand, may contribute to the enhanced MCC observed in the normal lung (5).

It is difficult to discern from this study the length of time that a single aerosolized UTP treatment may be effective for enhancing MCC. On the one hand, the time course of sputum production shows the peak production occurring immediately to 30 min after UTP inhalation (8). This seems to correspond to the acute speeding of clearance we find in the first $30 \mathrm{~min}$ after treatment. However, the change in clearance rate at or about $50 \mathrm{~min}$ on the UTP treatment days is also likely to be a reflection of near complete clearance of labeled particles from the bronchial airways. The UTP may continue to be active beyond this time period, but the loss of tracer from ciliated airways makes such action undetectable. For this reason it may be that the higher dose of UTP has a longer period of action but, again, is undetectable. Sabater and coworkers (12) recently showed a dose-dependent effect of single doses of aerosolized UTP $\left(10^{-1}\right.$ and $\left.10^{-2} \mathrm{M}\right)$ on tracheal mucus velocity (TMV) over a 4-h period in sheep. In these studies the greatest increase in TMV was seen 15 to $30 \mathrm{~min}$ after aerosolized UTP treatment. The enhanced TMV over control was still present, however, at $2 \mathrm{~h}$ posttreatment for both doses of UTP, and at 4 $\mathrm{h}$ posttreatment for the higher dose (comparable to $50 \mathrm{mg} / \mathrm{ml}$ ).

The enhanced clearance rates after UTP treatment were more dramatic in the central lung regions, suggesting that under the aerosol delivery conditions used here, i.e., tidal breathing from a Pari LC Plus nebulizer, the larger bronchial airways may be most affected. The finding that the UTP effect on whole lung clearance was most dramatic in those subjects with the higher $\mathrm{C} / \mathrm{P}$ ratio also suggests a greater effect to the larger airways. These regional effects may be dependent on the conditions of both the radiolabeled and UTP aerosol inhalations and particle sizes. The particle size and breathing conditions 
for the ${ }^{99 \mathrm{~m}} \mathrm{Tc}$-iron oxide particles were chosen to enhance airway deposition. Our $24 \mathrm{~h}$ retention values (Table 1) suggest that as much as $60 \%$ of the particles were deposited on ciliated airway surfaces. The particle size for the UTP aerosol was only slightly smaller than the ${ }^{99 \mathrm{~m}} \mathrm{Tc}$-iron oxide particles (3.6 versus $4.0 \mu \mathrm{m}$ ), suggesting that both may have distributed similarly along the bronchial tree in each subject. Had we chosen particle sizes and breathing conditions to maximize particle deposition of both the labeled marker and the nebulized UTP in small airways of the lung (13), we may have seen a more dramatic effect of UTP on the peripheral lung region. It should also be emphasized that the peripheral regions, as defined by our gamma camera analysis, had a greater percentage of alveolar to total deposition than central regions (the mean 24-h retention for peripheral regions versus central regions on all study days $=0.43$ versus 0.35 , respectively). Because alveolar clearance of particles occurs very slowly (weeks to months) and is unlikely to be affected by UTP treatment, this difference in deposition distribution would tend to reduce the effect of treatment on peripheral clearance rates over all periods of observation.

The frequency of spontaneous coughing was increased in response to aerosolized UTP treatment here and in the dose escalation safety studies (8). However, despite the increased coughing, Clr was not dependent on cough frequency in the multivariate analysis. Similarly, despite the much greater cough frequency seen with the higher dose of UTP, the Clr from any lung region was not different from that of the lower dose. The increased cough frequency with the higher concentration of UTP may be another reflection of increased mucus production at this dose. Cough can be effective at enhancing secretions in chronic bronchitics with more severe disease and likely more hypersecretion than those studied here (14). However, in a previous study we showed that voluntary, controlled cough $(60$ controlled coughs over the first $60 \mathrm{~min}$ of MCC measurements) was not effective at enhancing MCC in smokers with normal lung function such as those of our present study (15). Thus, it is unlikely that increased cough is solely responsible for the enhancement of clearance by UTP, but it may have aided clearance once UTP had enhanced or mobilized secretions in the airways. As an example of how cough may work in concert with UTP effects on secretions, we showed recently that when ciliary function is lost, i.e., in PCD, UTP aids in the clearance of secretions by cough (6). In this case cough is the primary, if not only, means by which secretions are cleared from the airways but UTP likely enhanced mobilization or clearability of the secretions for cough clearance to be enhanced in these patients with PCD.

The limited safety assessments of this study suggest that the UTP treatments, especially at the low 20-mg dose, are well tolerated. More extensive safety assessment at even higher doses in similar patients has shown no serious adverse events (8). There appears to be a dose effect on cough frequency, oxyhemoglobin desaturation, and MMEF that is likely a reflection of increasing secretions at the higher 100-mg dose of UTP. Dose escalation studies (8) have also shown greater sputum production with escalating doses of UTP. Yet we have shown here that the low dose of UTP $(20 \mathrm{mg})$ produces substantial enhancement of MCC rates with minimal side effects.

Smokers with mild chronic bronchitis, such as those studied in the present study, have been shown previously to have mildly depressed mucociliary clearance compared with normal $(16,17)$. We have shown in the current study and other studies that a relatively low dose of aerosolized UTP is well tolerated, enhances the rate of MCC, and enhances sputum expectoration in these subjects (8). These studies suggest that
$\mathrm{P}_{2} \mathrm{Y}_{2}$ agonists have therapeutic potential for treating the impairment of mucociliary clearance associated with obstructive lung diseases, such as chronic bronchitis, cystic fibrosis, and PCD. Because UTP is susceptible to enzymatic degradation within the airways, other resistant $\mathrm{P}_{2} \mathrm{Y}_{2}$ agonists being developed may be more appropriate for treating chronic obstructive lung diseases. However, the ability of UTP to rapidly stimulate MCC and to thereby enhance the quality of expectorated sputum (8) may make this compound ideally suited as a single-use, sputum induction agent for acquiring diagnostic specimens of airway lining fluid (18).

\section{References}

1. Mason SJ, Paradiso AM, Boucher RC. Regulation of transepithelial ion transport and intracellular calcium by extracellular ATP in human and cystic fibrosis airway epithelium. Br J Pharmacol 1991;103:1649-1656.

2. Benali R, Pierrot D, Zahm M, de Bentzmann S, Puchelle E. Effect of extracellular ATP and UTP on fluid transport by human nasal epithelial cells in culture. Am J Respir Cell Mol Biol 1994;10:363-368.

3. Lansley AB, Sanderson MJ, Dirksen ER. Control of the beat cycle of respiratory tract cilia by $\mathrm{Ca}^{2+}$ and cAMP. Am J Physiol 1992;263:L232-L242.

4. Lethem MI, Dowell ML, Van Scott M, Yankaskas JR, Egan T, Boucher RC, Davis CW. Nucleotide regulation of goblet cells in human airway epithelial explants: normal exocytosis in cystic fibrosis. Am J Respir Cell Mol Biol 1993;9:315-322.

5. Olivier KN, Bennett WD, Hohneker KW, Zeman KL, Edwards LJ, Boucher RC, Knowles MR. Acute safety and effects on mucociliary clearance of aerosolized uridine 5 'triphosphate \pm amiloride in normal human adults. Am J Respir Crit Care Med 1996;154:217-223.

6. Noone PG, Bennett WD, Regnis JA, Zeman KL, Carson JL, King M, Boucher RC, Knowles MR. Effect of aerosolized uridine-5'-triphoshate (UTP) on airway clearance with cough in patients with primary ciliary dyskinesia. Am J Respir Crit Care Med 1999;160:144-149.

7. Picher M, Boucher RC. Diadenosine polyphosphates hydrolysis in human airways. Pediatr Pulmonol Suppl 1998;17:288.

8. Shaffer C, Jacobus K, Foy C, Pue C, Donohue J, Bennett W, Ye H, Graham $\mathrm{C}$, Noone P, Drutz D. Controlled clinical studies indicate that INS316 (uridine-5'-triphosphate), a P2Y2 receptor agonist stimulates mucociliary clearance and enhances sputum expectoration [abstract]. Am J Respir Crit Care Med 1998;157:A796.

9. Kim CS, McDonald R, Sackner MA. Generation and characterization of sulfate aerosols for laboratory studies. Am Ind Hyg Assoc J 1981;42: 521-528.

10. Ebert RV, Terracio MJ. The bronchiolar epithelium in cigarette smokers: observations with the scanning electron microscope. Am Rev Respir Dis 1975;111:4-11.

11. Lumsden AB, McLean A, Lamb D. Goblet and Clara cells of human distal airways: evidence for smoking induced changes in their numbers. Thorax 1984;39:844-849.

12. Sabater JR, Mao YM, Shaffer C, James MK, O'Riordan TG, Abraham WM. Aerosolization of $\mathrm{P}_{2} \mathrm{Y}_{2}$-receptor agonists enhances mucociliary clearance in sheep. J Appl Physiol 1999;87:2191-2196.

13. Anderson M, Philipson K, Svartengren M, Camner P. Human deposition and clearance of $6 \mu \mathrm{m}$ particles inhaled with an extremely low flow rate. Exp Lung Res 1995;21:187-195.

14. Oldenburg FA, Dolovich MB, Montgomery JM, Newhouse MT. Effect of postural drainage, exercise and cough on mucus clearance in chronic bronchitis. Am Rev Respir Dis 1979;120:739-745.

15. Bennett WD, Chapman WF, Gerrity TR. Ineffectiveness of cough for enhancing mucus clearance in asymptomatic smokers. Chest 1992;102: 412-416.

16. Vastag E, Matthys H, Kohler D, Gronbeck L, Daikeler G. Mucociliary clearance and airways obstruction in smokers, ex-smokers and normal subjects who never smoked. Eur J Respir Dis 1985;66(Suppl 139): 93-100.

17. Goodman RM, Yergin BM, Landa JF, Golinvaux MH, Sackner MA. Relationship of smoking history and pulmonary function tests to tracheal mucous velocity in nonsmokers, young smokers, ex-smokers, and patients with chronic bronchitis. Am Rev Respir Dis 1978;117: 205-214.

18. Tockman MS, Gupta PK, Myers JD, Frost JK, Baylin SB, God EB, Mulshine JL. Sensitive and specific monoclonal antibody recognition of human lung cancer antigen on preserved sputum cells: a new approach to early lung cancer detection. J Clin Oncol 1998;6:1685-1693. 